\title{
Micromechanical Characterization of Complex Polypropylene Morphologies by HarmoniX AFM
}

\author{
S. Liparoti, ${ }^{1}$ A. Sorrentino, ${ }^{2}$ and V. Speranza ${ }^{1}$ \\ ${ }^{1}$ Department of Industrial Engineering, University of Salerno, Via Giovanni Paolo II 132, 84084 Fisciano, Italy \\ ${ }^{2}$ Institute for Polymers, Composites and Biomaterials (IPCB-CNR), Via Previati 1/C, 23900 Lecco, Italy \\ Correspondence should be addressed to S. Liparoti; sliparoti@unisa.it
}

Received 30 January 2017; Revised 10 March 2017; Accepted 21 March 2017; Published 6 April 2017

Academic Editor: Domenico Acierno

Copyright (C) 2017 S. Liparoti et al. This is an open access article distributed under the Creative Commons Attribution License, which permits unrestricted use, distribution, and reproduction in any medium, provided the original work is properly cited.

\begin{abstract}
This paper examines the capability of the HarmoniX Atomic Force Microscopy (AFM) technique to draw accurate and reliable micromechanical characterization of complex polymer morphologies generally found in conventional thermoplastic polymers. To that purpose, injection molded polypropylene samples, containing representative morphologies, have been characterized by HarmoniX AFM. Mapping and distributions of mechanical properties of the samples surface are determined and analyzed. Effects of sample preparation and test conditions are also analyzed. Finally, the AFM determination of surface elastic moduli has been compared with that obtained by indentation tests, finding good agreement among the results.
\end{abstract}

\section{Introduction}

The accurate characterization of mechanical properties of nanoheterogeneous materials, such as nanocomposites, biological cells, and multiphase polymers at the nanometric length scale, is a very important task $[1,2]$. In the last decade, several methods based on the probe-indentation techniques have been proposed. Indentation is probably the most known and used of these techniques to determine the local mechanical properties of sample surfaces. It is based on the application of a local deformation by means of an indenter; the resistance to indentation and the indentation depth are continuously monitored. Data are then analyzed adopting theoretical models to determine Young's modulus and the hardness of the sample. Several methods have been proposed to analyze the data in order to determine the hardness and elastic modulus [3]. The Loubet model is recognized to be more effective in determining the elastic modulus of strong viscoelastic materials (i.e., soft or biological materials) $[4,5]$, whereas the method by Pharr et al. $[6,7]$ is a more general one; it is applied on several materials with elastic behavior and it is implemented in the software of most indentation instruments. The literature results generally show that when the viscoelasticity can be neglected (i.e., polymers with high crystalline degree), the standard Oliver and Pharr method provides a very good approximation of the modulus for the majority of the analyzed polymer materials $[8,9]$.

Indentation has been successfully applied to several polymers, such as poly(methyl methacrylate) [10], and polymer systems [11-20], such as blends [21], copolymers [22, 23], composites [24, 25], bone cement [26], and multilayer systems [27]. However, its applicability is strictly limited by the probe dimension that allows spatial resolution of the order of tens of microns and does not allow the reconstruction of an accurate mapping of the sample surface. Furthermore, the measurement of mechanical properties by this technique is time-consuming, since the largest part of measurement time is devoted to the approach of the sample surface [28]. More recently, Atomic Force Microscopy (AFM) based techniques (HarmoniX and Peak Force) have been proposed to evaluate both qualitative and quantitative nanometric-resolved maps of the mechanical properties. They provide a quantitative characterization of adhesion, friction, energy dissipation, and mechanical modulus and part of other relevant properties like the critical load. In addition, these techniques are able to simultaneously provide topographic maps (from tens of nanometers up to microns) of the sample allowing a direct correlation among mechanical and morphological sample 
properties. Both AFM based methods, HarmoniX and Peak Force, are appropriate for the mechanical characterization of soft matter [29, 30]. In particular, HarmoniX technique operates in tapping mode and makes use of specifically designed cantilever geometries with an out-of-axis tip [31, 32]. The measurements of the vertical (topography) and torsional (friction) deflection at different frequencies allow us to separate the two signals and to have a complete and contemporary characterization of both mechanical and morphological properties during the scanning [31,32]. In the case of HarmoniX measurement, the mechanical properties are obtained applying a theoretical model to the acquired data [33]. This technique has been proposed to characterize carbon black-filled hydrogenated nitrile butadiene rubber [34], soft and hard segments of polyurethanes [35], and catalysts [36].

Generally, the application of AFM based techniques is limited to the mechanical characterization of homogeneous samples, and only few papers are devoted to the characterization of samples having complex morphology distribution [30].

In this paper, we intend to demonstrate the applicability of HarmoniX AFM technique to the characterization of molded polymer samples with complex, nonuniform morphologies [37-42], which could influence the mechanical properties of the final object $[28,43,44]$. To accomplish this objective, a series of HarmoniX tests have been performed on selected polypropylene molded samples. These samples have been chosen to highlight the sensitivity of this technique to the variations in morphologies normally found in molded thermoplastic samples [37, 38, 41, 42, 45]. HarmoniX tests have been conducted with different scan sizes and resolutions on samples prepared in different ways (i.e., etching procedures), with the objective of studying the relative influence of the preparation methods on the obtained results. The values of the elastic modulus obtained by HarmoniX tests have been also compared to the values obtained by independent microindentation tests carried out on the same samples.

\section{Experimental}

2.1. Materials and Methods. A commercial isotactic polypropylene (iPP, Basell T30G), with an average molecular weight of $\mathrm{Mw}=376,000$ and a polydispersity index of $\mathrm{Mw} / \mathrm{Mn}=$ 6.7, was adopted to prepare the injection molded samples. A complete mechanical, rheological, and thermal characterization of this polymer can be found elsewhere [46-52]. Injection molding tests were carried out adopting a melt temperature of $220^{\circ} \mathrm{C}$, a mold temperature of $25^{\circ} \mathrm{C}$, and a packing pressure of 260 bar. A rectangular cavity having a length of $110 \mathrm{~mm}$, a width of $12.7 \mathrm{~mm}$, and a thickness of $1.5 \mathrm{~mm}$ was employed. Supplementary information about the cavity geometry is reported elsewhere $[28,38]$.

2.2. Sample Preparation. For the HarmoniX tests, small specimens were cut from the midplane of the molded objects along the flow direction. To obtain a smooth surface, the specimens were microtomed by a Leica microtome. The specimens were then chemically etched following the procedure reported by White and Bassett [53] and previously adopted on similar iPP samples $[37,38,42]$. In order to determine the effect of the etching procedure on the mechanical results, the samples were etched for different times.

2.3. HarmoniX AFM Characterization. For HarmoniX measurements, a standard NanoScope MultiMode V scanning probe microscope (Veeco, Santa Barbara, CA) equipped with T-shaped cantilevers (Bruker, Billerica, MA) having a spring constant of $1.58 \mathrm{Nm}^{-1}$ and a vertical resonance frequency of $\sim$ $60 \mathrm{kHz}$ has been employed. Topography and elastic modulus images were collected at $0.5 \mathrm{~Hz}$ of scanning rate and with different scan resolutions.

In order to obtain reliable results of mechanical properties through AFM, the "relative calibration method" was adopted; details about the "relative method" can be found in the instrument manual provided by Gojzewski et al. [54]. In the "relative method," each cantilever/tip combination needs to be calibrated to obtain (quantified) elastic modulus values of unknown samples. To take into account the expected elastic modulus range on the analyzed areas, two reference samples were selected for calibration: polystyrene and high density polyethylene with elastic modulus of $2.5 \mathrm{GPa}$ and $0.5 \mathrm{GPa}$, respectively, as indicated by Gojzewski et al. The calibration was always carried out before any measurements of the samples characterized in this work. The relative method allowed reducing some important propagating errors, especially regarding the uncertainty of the cantilever spring constant and the tip radius measurements [54].

The NanoScope software version 7.30 adopted for HarmoniX measurements gives values of elastic modulus (named DMTModulus in the AFM acquisitions) applying the Derjaguin-Muller-Toporov (DMT) model to the acquired data [33].

Scan sizes of $5 \times 5 \mu \mathrm{m}, 10 \times 10 \mu \mathrm{m}$, and $20 \times 20 \mu \mathrm{m}$ were adopted to highlight the structures developed in the different zones.

The elastic modulus maps were analyzed in terms of the distribution of moduli over the investigated area; the maps were elaborated by bearing analysis implemented in the NanoScope software. The values of elastic modulus reported in this work have been obtained considering at least ten maps.

2.4. Microindentation. The indentation modulus and hardness measurements have been performed by Nano Test ${ }^{\mathrm{TM}}$ Platform (Micro Materials Ltd.), using a three-sided Berkovich tip. For each sample, at least 5 imprints have been made. The following test parameters were used for all samples: minimum load $=0.2 \mathrm{mN}$; maximum load $=120 \mathrm{mN}$; loading and unloading rate $=2 \mathrm{mN} / \mathrm{s}$; holding time of the maximum load $60 \mathrm{~s}$. The Nano Test software gives the hardness and elastic modulus of iPP injection molded samples [9], according to Oliver and Pharr's method $[6,7]$.

\section{Results and Discussion}

3.1. Effect of the Etching Procedure. As mentioned in the previous section, in order to analyze an injection molded 

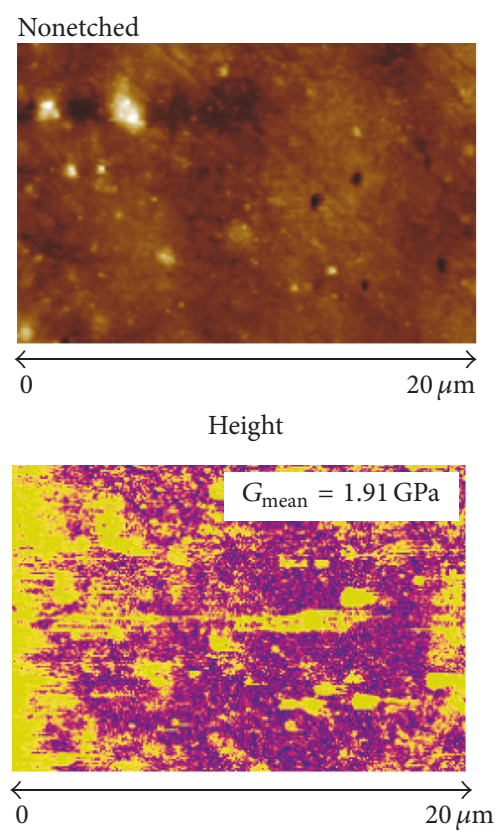

DMTModulus

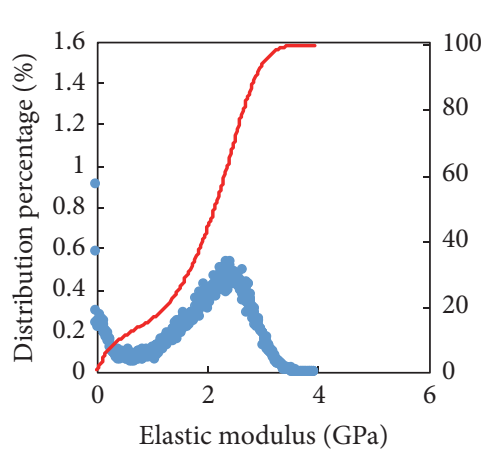

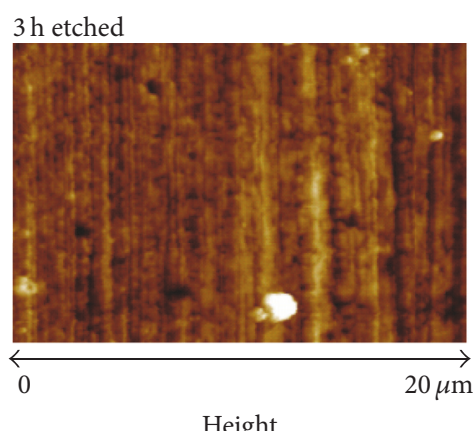

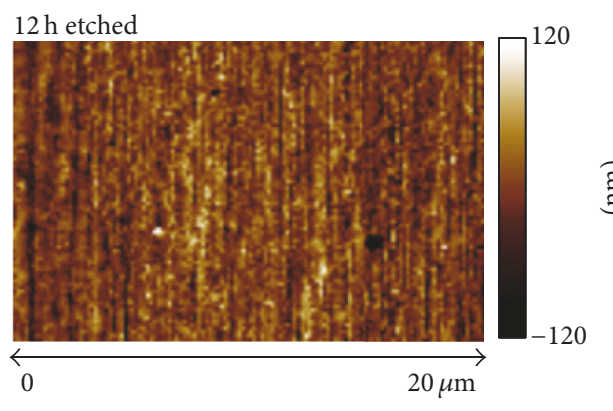

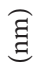

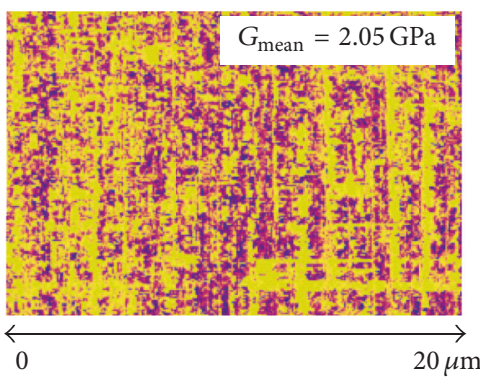

DMTModulus

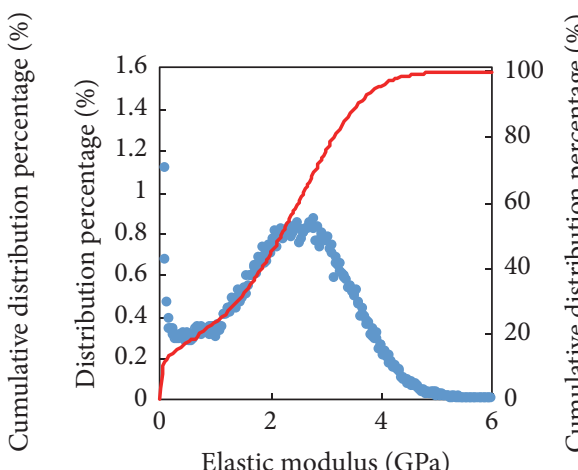

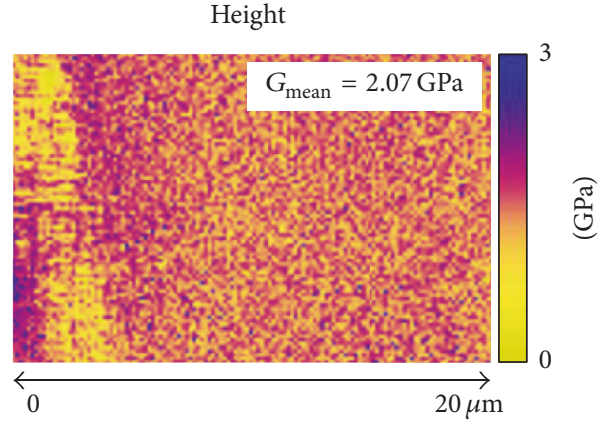

DMTModulus

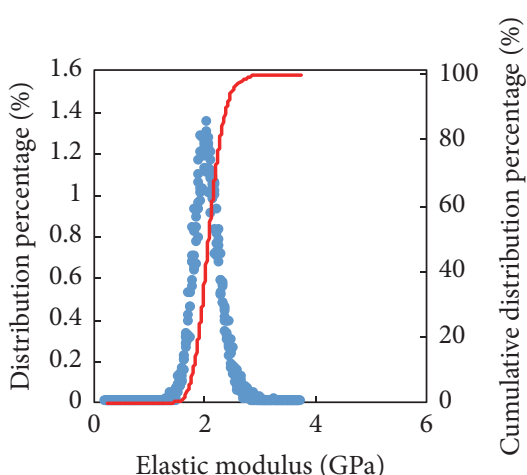

FIGURE 1: Topography (height), elastic modulus map, and the corresponding elastic modulus distribution in the shear layer (200 $\mu \mathrm{m}$ from the sample surface) acquired on a nonetched sample and on a sample etched for different times ( $3 \mathrm{~h}$ and $12 \mathrm{~h}$ ). For each reported elastic modulus map, the elastic modulus average value is reported.

sample by AFM, it is necessary to prepare the sample. The described microtome procedure induces the formation of a plastic zone on the surface to be analyzed that could hide the representative features developed during the injection molding process and could induce a noncorrect evaluation of the mechanical properties. Generally, an etching procedure has to be adopted to highlight the structures developed in molded iPP samples, since the etching procedure removes part of the amorphous phase entrapped between the polymer crystals as well as the resultant of the mechanical cutting. To reduce the impact of the preparation on the sample analysis, different times of chemical etching have been adopted. This also allows us to study the effect of the etching time on the mechanical characteristics of the sample [30].

Figure 1 shows the topography taken on the shear layer of the injection molded sample exposed to the chemical etching solution for different times, $0 \mathrm{~h}, 3 \mathrm{~h}$, and $12 \mathrm{~h}$. From the first image row of Figure 1, which shows an average roughness of $12.3 \pm 3.5 \mathrm{~nm}$, it is evident that the morphology could not be clearly detected on the nonetched sample; this observation demonstrates the presence of an amorphous layer on the top of the crystalline region $[30,55]$. As expected, by increasing the etching time, the morphology, characterized by crystalline fibrillar structures [56, 57], becomes more clear and definite. The roughness, after $3 \mathrm{~h}$ etching, is 14.3 $\pm 3.0 \mathrm{~nm}$; therefore, the roughness shows a slightly higher value with respect to the roughness of the nonetched sample; the increase of roughness is due to the presence of areas in which the etching probably has shown different rates between amorphous and crystallized polymers [30]. With the increase of etching time up to $12 \mathrm{~h}$, the roughness decreases down to $9.7 \pm 0.1 \mathrm{~nm}$, since the amorphous parts have been efficiently removed and the etching procedure is effective also on the crystalline structures. The fibrils, clearly detectable after $12 \mathrm{~h}$ etching, have a mean thickness of about $360 \mathrm{~nm}$. However, the observation of topography maps suggests that the morphology of the shear layer is detected already applying an intermediate etching time $(3 \mathrm{~h})$. 


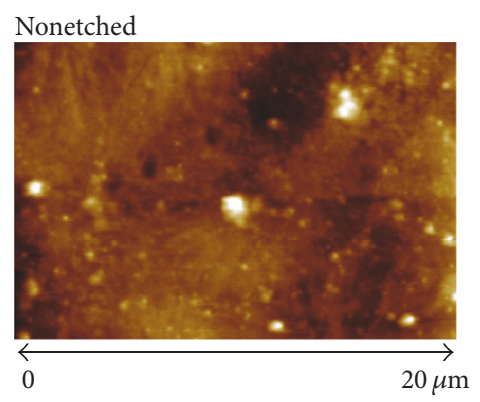

Height

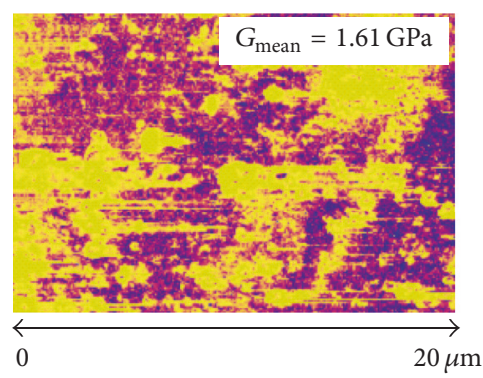

DMTModulus

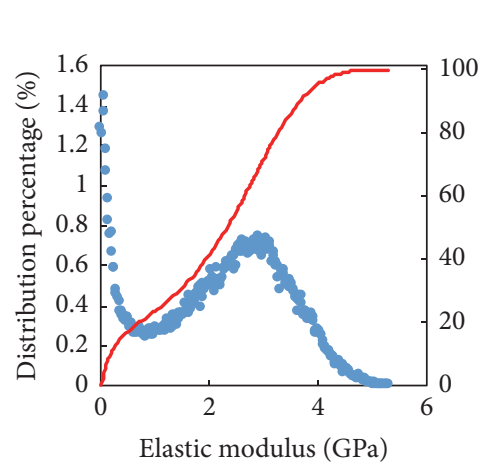

$3 \mathrm{~h}$ etched

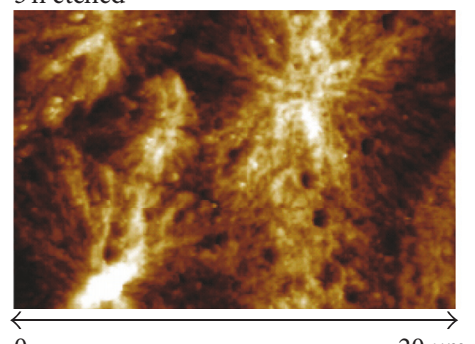

$\overleftarrow{0}$

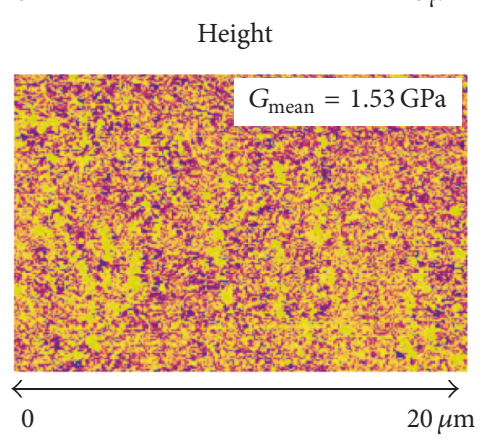

0
DMTModulus

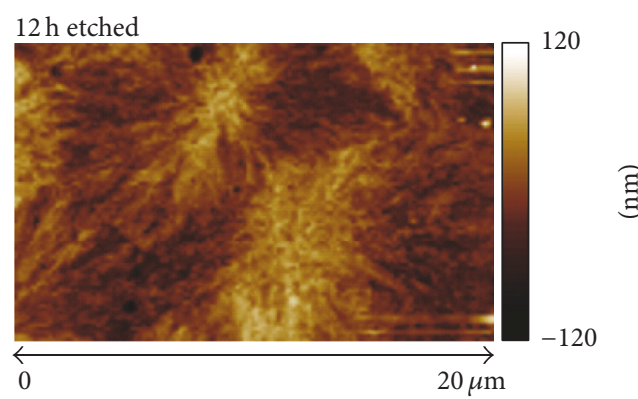

Height

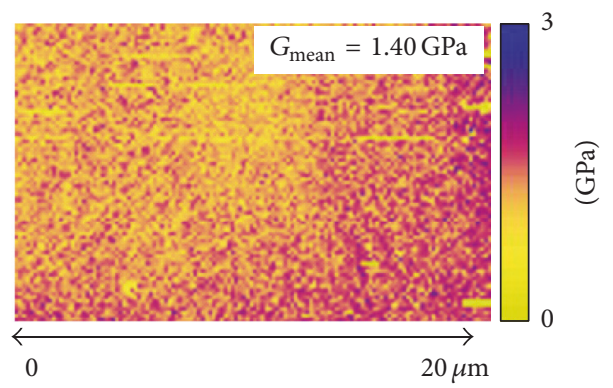

DMTModulus
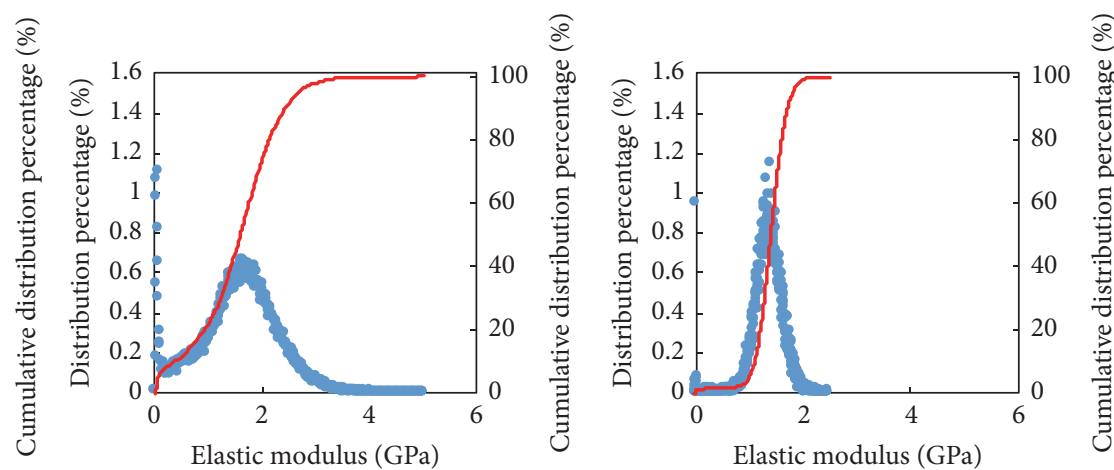

FIGURE 2: Topography (height map), elastic modulus map, and the corresponding elastic modulus distributions in the spherulitic core (750 $\mu \mathrm{m}$ from the sample surface) acquired on a nonetched sample and on a sample etched for different times ( $3 \mathrm{~h}$ and $12 \mathrm{~h}$ ). For each reported elastic modulus map, the elastic modulus average value is reported.

Figure 1 shows also the elastic modulus maps and the corresponding elastic modulus distributions obtained by applying the bearing analysis on the scanned area. The cumulative curves of the distributions, which represent the percentage of the area with modulus lower than a reference value, are also reported (red line).

If no etching has been applied to the sample, a lower average value of elastic modulus is measured and a wider distribution with a significant contribution of a soft part is observed. Adopting $3 \mathrm{~h}$ etching time, the percentage of the investigated area with values of elastic modulus higher than the average increases, whereas the contribution of the soft part is essentially the same of the nonetched sample, as also observed from the topography. The contribution of the soft part disappears only adopting $12 \mathrm{~h}$ etching time; in this case, symmetric bell shaped curves are obtained. The elastic modulus distributions, being narrow and symmetric, could be completely characterized by using the average and the variance.
The elastic modulus distributions also show that the average elastic modulus values become higher with the increase of etching time. Since the crystalline structures generally give higher modulus values than the amorphous ones [30], it is possible to conclude that the etching procedure is very effective in removing the amorphous part and all the resultants of the microtome procedure. This finding is also confirmed by the values of adhesion force that significantly decrease from $50 \mathrm{nN}$ to $7 \mathrm{nN}$ for the nonetched sample and for the sample etched with $12 \mathrm{~h}$ etching time, respectively; generally, high values of adhesion force are due to the viscous properties of an almost amorphous polymer in the nonglassy state [58].

Being the molded sample characterized by a complex morphology along the sample thickness, the effect of the etching time has been investigated also in the spherulitic core, as reported in Figure 2.

Figure 2 shows that in the spherulitic core the dependence of morphology and mechanical behavior on the etching time is similar to that observed in the shear layer. Also, in this 
area, clear and definite morphology can be detected by the topography already selecting $3 \mathrm{~h}$ as etching time. Without applying the etching procedure, the average roughness is 12 $\pm 5.0 \mathrm{~nm}$; after $3 \mathrm{~h}$ etching time, the average roughness is the highest one, $30.0 \pm 5.0 \mathrm{~nm}$, because the spherulites centers appear higher than the surroundings. This is probably due, again, to the etching rate that is different in the amorphous and in the crystalline areas of the investigated window. With $12 \mathrm{~h}$ etching time, the roughness is $14.9 \pm 1.3 \mathrm{~nm}$, since in this case the etching procedure is effective also in the crystalline regions.

The elastic modulus distribution is bell shaped and narrow with $12 \mathrm{~h}$ of etching time.

The analyses of the two zones, the shear and the spherulitic core, clearly show that, by only adopting $12 \mathrm{~h}$ etching time, it is possible to obtain a unimodal and narrow elastic modulus distribution. The average values are more confident in describing the mechanical behavior of the investigated area, since the contribution of the soft part at the topmost molecules, due to the cutting procedure, has been removed.

Since the chemical etching is effective in removing the softer contribution due to the cutting procedure and HarmoniX AFM gives the mechanical properties of the material beneath the tip, HarmoniX AFM measurements are able to assess the effect of the injection molding process conditions on the mechanical characteristics of the final object $[28,30]$. Furthermore, with $12 \mathrm{~h}$ etching time, the topographic image is significantly improved. For all these reasons, $12 \mathrm{~h}$ etching time has been adopted for all the analyzed samples.

3.2. Effect of the Scan Size. An appropriate choice of the scan size and resolution is also important for the characterization of the sample morphology and mechanical properties. Generally, the mechanical properties are related to the crystalline and amorphous phase content and to the developed morphology [30]. In principle, AFM is able to resolve information up to the nanoscale level. However, it is necessary to take into account also the characteristic dimensions of the morphological elements in order to obtain a reliable mechanical representation. For nonhomogeneous samples or when the dimensions of the morphological elements change with the position along the sample thickness, the choice of scan size and thus scan resolution is not a simple task. An appropriate experimental verification is necessary in order to avoid lowresolution acquisitions or time-consuming tests.

Figure 3 shows the topography and elastic modulus maps and the elastic modulus distribution in the zone of spherulitic core $(750 \mu \mathrm{m}$ from the sample surface, i.e., sample midplane) obtained with different scan areas. In particular, three different scan areas have been selected: $25 \mu \mathrm{m}^{2}, 100 \mu \mathrm{m}^{2}$, and $400 \mu \mathrm{m}^{2}$ (from left to right in Figure 3). All the three maps have been acquired setting the same number, that is, 128 , of lines per image and of points per line. Thus, for each selected scan area, the map is acquired considering $128 \times 128$ measuring points. To highlight the importance of the scan size on the mechanical properties measurements, the moduli distributions have been evaluated not only on the whole area but also considering a smaller area; in particular, in Figure 3, the square boxes indicate areas of $25 \mu \mathrm{m}^{2}$. The elastic modulus
TABLE 1: Average elastic modulus evaluated by HarmoniX AFM on different areas with different measuring points.

\begin{tabular}{lccc}
\hline & $25 \mu \mathrm{m}^{2}$ & $100 \mu \mathrm{m}^{2}$ & $400 \mu \mathrm{m}^{2}$ \\
\hline $128 \times 128$ & $1.36 \pm 0.17 \mathrm{GPa}$ & $1.38 \pm 0.30 \mathrm{GPa}$ & $1.39 \pm 0.45 \mathrm{GPa}$ \\
$64 \times 64$ & $1.33 \pm 0.25 \mathrm{GPa}$ & $1.32 \pm 0.32 \mathrm{GPa}$ & - \\
$32 \times 32$ & $1.24 \pm 0.15 \mathrm{GPa}$ & - & - \\
\hline
\end{tabular}

distributions and cumulative curves reported in the figure are, for each map, evaluated relatively only to the area, $25 \mu \mathrm{m}^{2}$, enclosed in the square box; this area corresponds, for the leftmost elastic modulus map, to the whole scan area. The elastic modulus distributions and cumulative curves, relative to the square boxes, are evaluated taking into account the numbers of measuring points of $128 \times 128,64 \times 64$, and 32 $\times 32$ from left to right.

The smallest scan area, that is, $25 \mu \mathrm{m}^{2}$, allows capturing the finest details of the investigated morphology, as shown in the topography. The biggest scan area, that is, $400 \mu \mathrm{m}^{2}$, allows observing more than one typical structure, that is, spherulites, present in the investigated area. With respect to the areas enclosed in the square boxes, the comparison among the elastic modulus maps suggests different values of elastic modulus. However, deeper investigations based on the elastic modulus distributions are required. The elastic modulus distributions are bell shaped in all the acquisitions reported in Figure 3. Furthermore, the distributions are narrow, similar to those reported in Figures 1 and 2. Table 1 reports values of average elastic modulus obtained considering the distribution evaluated not only on the areas enclosed in the square boxes, whose values are reported in the first column of Table 1, but also on bigger areas, that is, $100 \mu \mathrm{m}^{2}$ and $400 \mu \mathrm{m}^{2}$.

The analysis of elastic modulus distributions demonstrates that only small differences can be detected by changing the area or the number of measuring points; these differences are certainly within the experimental accuracy of the test method. Therefore, to obtain confident values for elastic modulus, the analysis of the distribution and cumulative curves is necessary since it is not possible to compare mechanical characteristics among different samples through the observation of the maps.

To verify this finding in other zones of the injection molded sample, a wider scan area of $3600 \mu \mathrm{m}^{2}$, in the transition zone, in which different morphological structures are present, that is, spherulites and fibrils, has been investigated adopting $128 \times 128$ points per line. The results are shown in Figure 4.

Figure 4 shows that very similar distributions have been obtained in the three areas of $400 \mu \mathrm{m}^{2}$ and their average values are very close to the average value obtained considering the whole investigated area $\left(3600 \mu \mathrm{m}^{2}\right)$, that is, $1.85 \pm$ $0.13 \mathrm{GPa}$.

In the following, all the maps are acquired with a $400 \mu \mathrm{m}^{2}$ scan area and $128 \times 128$ measuring points since this setting allows us to obtain a reliable representation of both morphology and mechanical characteristics. Therefore, $128 \times 128$ points per line are sufficient to detect mechanical 

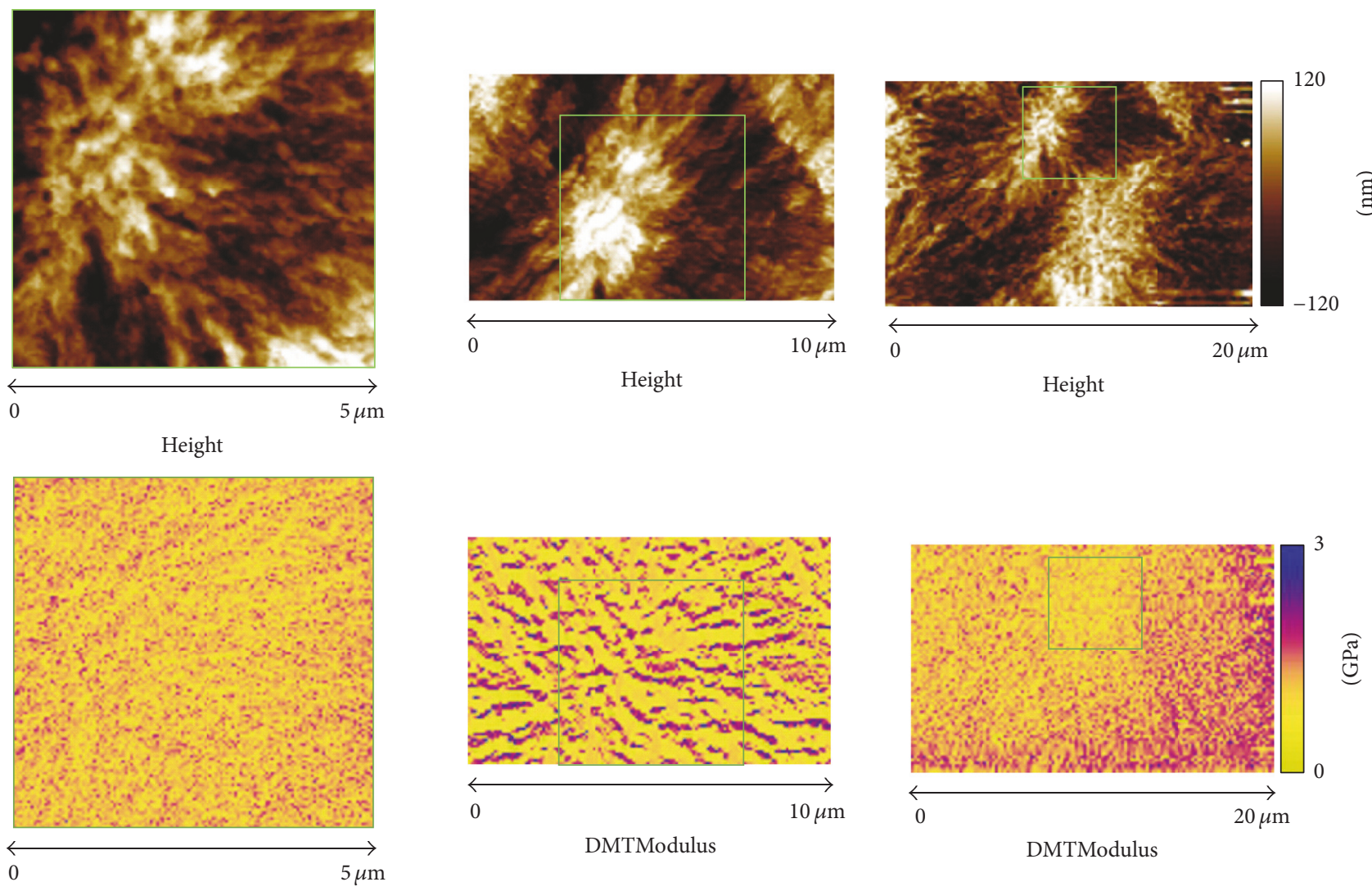

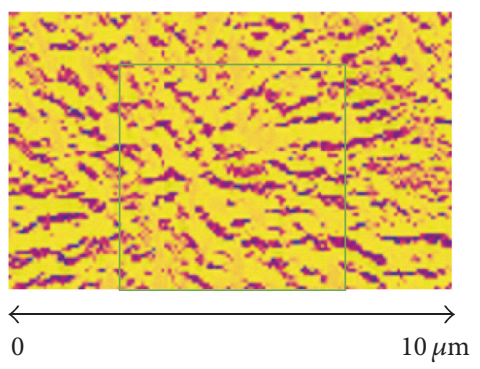

DMTModulus

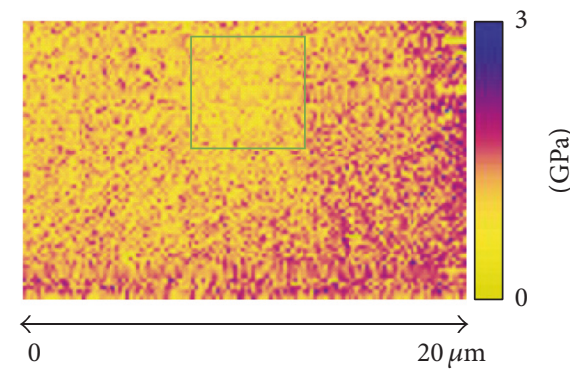

DMTModulus

DMTModulus
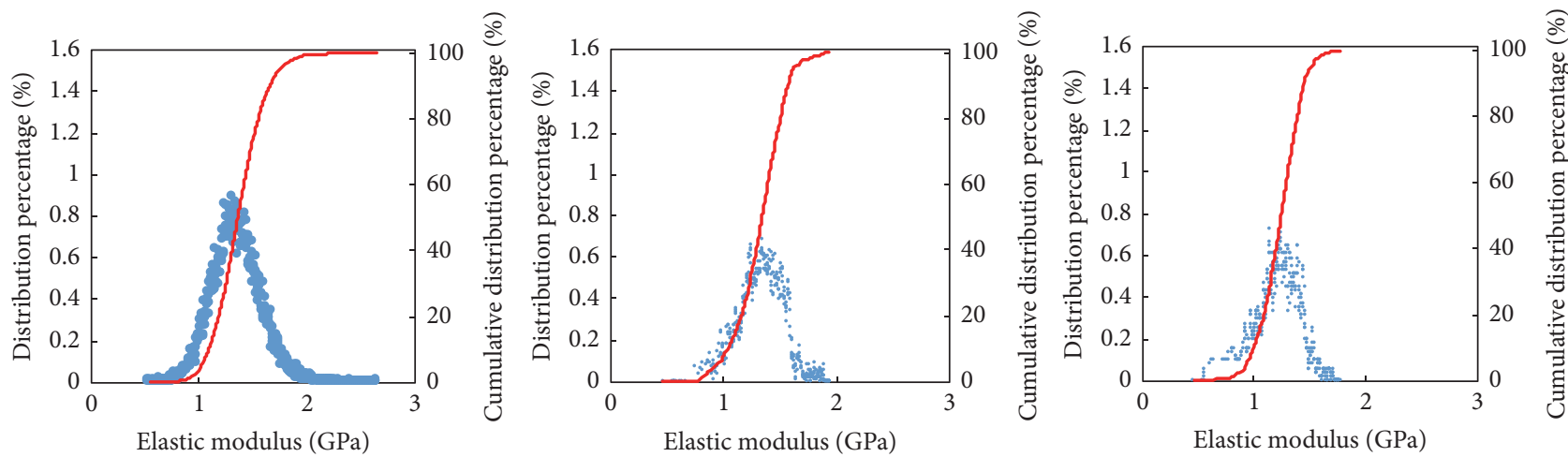

FIGURE 3: Effect of scan size and resolution on the topography (height map), elastic modulus map, and distribution acquired at $750 \mu \mathrm{m}$ from the sample surface. The elastic modulus distribution has been evaluated on the area enclosed in the square box.

properties of the smaller structures, that is, fibrils in the shear layer, keeping the acquisition time small.

\subsection{Mechanical Characterization by HarmoniX AFM. In} Figure 5, maps acquired in three selected positions $(600 \mu \mathrm{m}$, $510 \mu \mathrm{m}$, and $270 \mu \mathrm{m}$ distance from the sample surface) along the sample thickness are reported. In particular, the topography, the peak force, the adhesion, and elastic modulus maps with the corresponding elastic modulus distributions are reported in Figures 5(a)-5(e), respectively. The three topographies reveal typical morphological elements normally found in the melt processed semicrystalline polymers $[39,59$, 60]. In particular, a high crystalline nonoriented spherulitic morphology, generally obtained in sample crystallized under quiescent conditions, is presented in the left of Figure 5(a). In the middle of Figure 5(a), combined morphology, typical of transition zone, is reported. In the transition zone, whose presence is due to a high temperature melt flow that takes place in a confined geometry, the morphology evolves gradually from spherulitic to fibrillar (from the sample core to the wall). The strong temperature differences along the sample thickness allow molecular relaxation only over a part of the sample; therefore, some fibrils, that is, those placed at the border of the spherulitic core, are replaced by elongated spherulites. The result of this partial relaxation is the coexistence of different crystal morphologies separated 


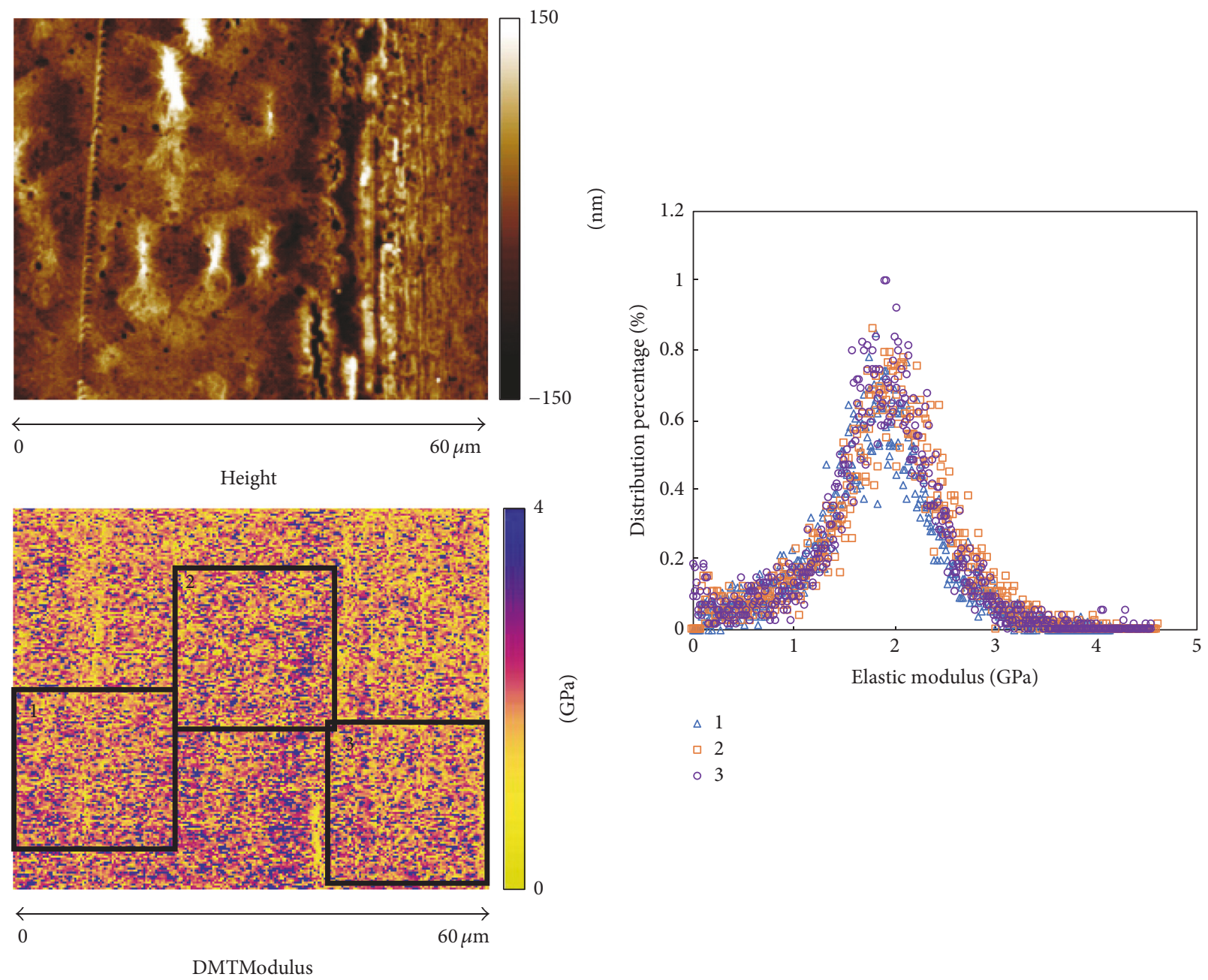

FIGURE 4: Effect of scan size and resolution on the elastic modulus map and distribution acquired at $270 \mu \mathrm{m}$ from the sample surface. The elastic modulus distribution has been evaluated on the area enclosed in the square box. The topography is also reported.

by transition regions $[41,61]$. Finally, closer to the sample surface, highly oriented fibrillar morphology has been found as reported in the right of Figure 5(a). These structures are very common in the areas where the melt solidifies at high cooling rate during intensive flow. Under these solidification conditions, high level of molecular orientation is frozen to form well ordinated and confined fibrillary crystals [62]. As highlighted in the topographies of Figure 5(a), the structures detected along the sample thickness, that is, the spherulites and the fibrils, have different organization and different orientations, and thus the elastic modulus could be expected to be influenced also by the molecular arrangement [28].

Figures 5(b) and 5(c) show maps of the peak force and adhesion force recorded in the same areas. The peak force is related to the maximum cantilever deflection, whereas the adhesion depends on the interaction among the probe and sample surface. Both values have to be considered in the calculation of modulus by the DMT model [31]. In order to obtain reliable measurements by applying the DMT model, an indentation depth similar to those measured during the calibration with the reference sample is generally required.
To that purpose, the peak force is kept almost the same as the reference sample in the three areas [29].

Figure 5(c) shows that a lower adhesion force with respect to the spherulitic core and the transition area characterizes the fibrillar area. As mentioned above, the value of the adhesion force can be related to the content of a softer phase, which can be due to the amount of amorphous phase or other soft crystalline phases (i.e., $\beta$-phase in iPP case [38, $48,63,64]$ ); therefore, one can conclude that the shear is characterized by a lower amount of soft phases with respect to the transition and the spherulitic core. The shear layer behavior is also due to the higher level of organization and molecular orientation.

Figures 5(d) and 5(e) show the elastic modulus maps and distribution of the investigated areas. The morphological elements present in the topographies (height images) of Figure 5(a) are also visible in the elastic modulus maps (Figure 5(d)). The oriented fibrils show higher moduli, whereas the spherulitic isotropic core shows the lowest moduli. In the transition zone, the moduli decrease gradually from the higher values of the shear layer to the lower values of 


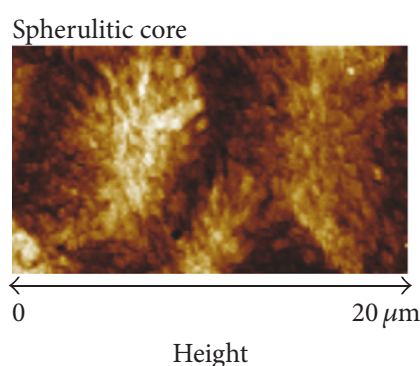

Spherulitic core

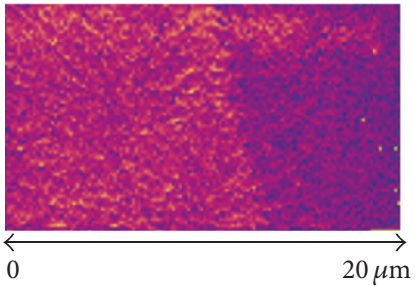

Peak force

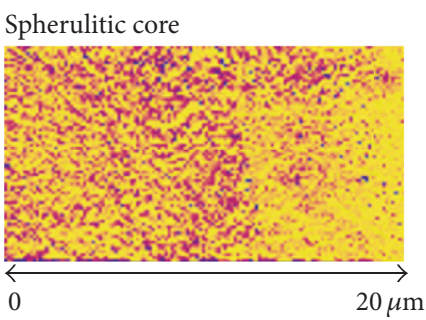

Adhesion

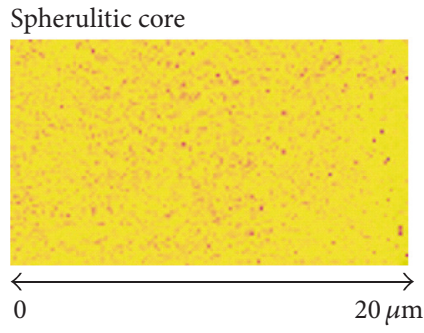

DMTModulus

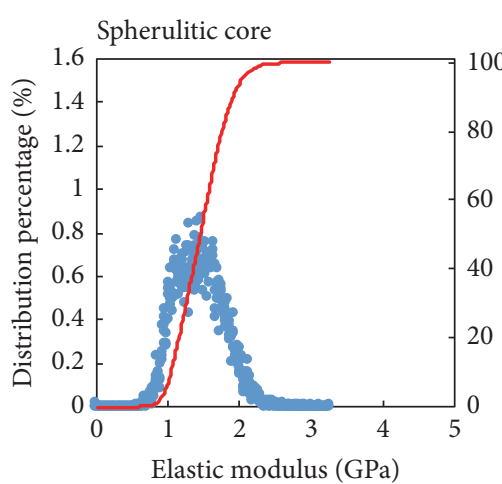

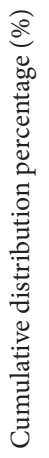
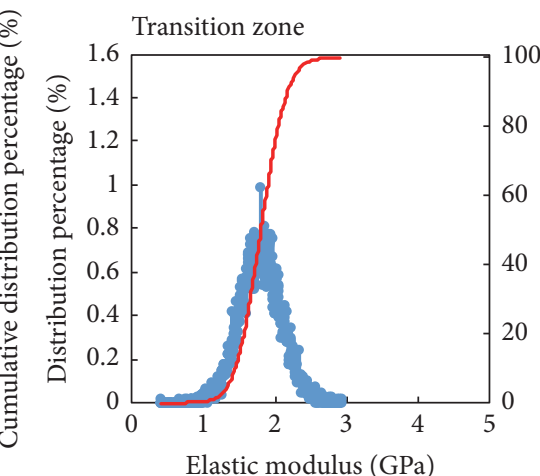

(e)

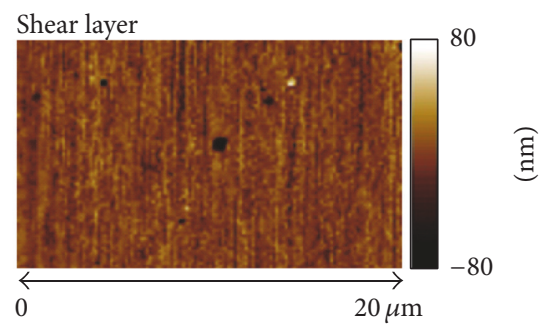

Height

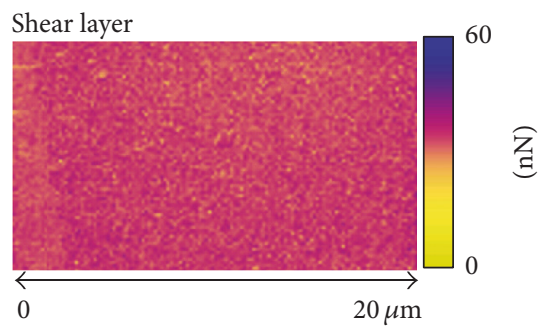

Peak force

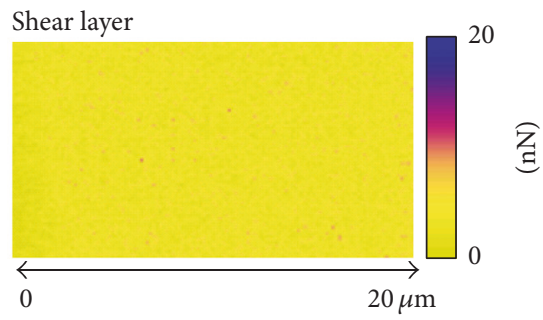

Adhesion

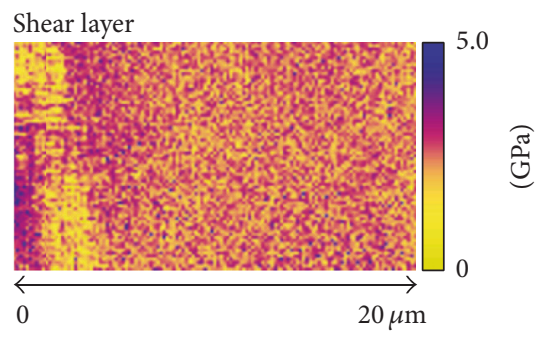

DMTModulus

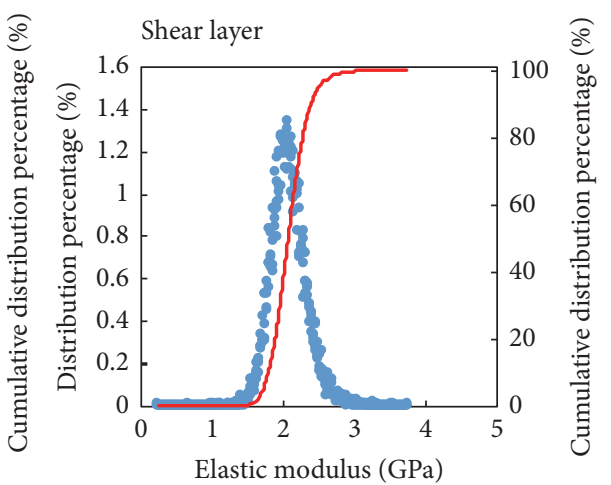

FIGURE 5: Representative maps of (a) topography (height), (b) peak force, (c) adhesion, and (d) elastic modulus and its distribution (e) obtained by HarmoniX AFM mode in the three different positions along the molded sample thickness $(600 \mu \mathrm{m}, 510 \mu \mathrm{m}$, and $270 \mu \mathrm{m}$ from the sample surface for spherulitic core, transition zone, and shear layer, resp.). 
TABle 2: Comparison between elastic moduli evaluated by HarmoniX AFM and indentation tests in different positions along the sample thickness.

\begin{tabular}{lccc}
\hline Test/zone & $\begin{array}{c}\text { Spherulitic } \\
\text { core }(\mathrm{GPa})\end{array}$ & $\begin{array}{c}\text { Transition } \\
\text { zone }(\mathrm{GPa})\end{array}$ & $\begin{array}{c}\text { Shear zone } \\
(\mathrm{GPa})\end{array}$ \\
\hline HarmoniX & $1.50 \pm 0.45$ & $1.80 \pm 0.47$ & $1.98 \pm 0.47$ \\
Nanoindentation & $1.67 \pm 0.50$ & $1.81 \pm 0.55$ & $2.00 \pm 0.48$ \\
\hline
\end{tabular}

spherulitic core. However, the average elastic modulus value is intermediate between the shear and the spherulitic core. Despite the higher adhesion level, which suggests higher content of softer phase, with respect to the spherulitic core, the elastic modulus is higher in the transition, probably, because the higher level of orientation in the transitional zone [38] compensates for the higher amount of soft phase.

The distributions shown in Figure 5(e) are bell shaped and narrow; they respect all the conditions, previously described, to obtain a reliable mechanical characterization for the investigated areas. The average values of elastic modulus, calculated from the distributions shown in Figure 5(e), are compared with the elastic modulus obtained by indentation tests carried out on the same sample positions in Table 2. Results of the two analyses are in good agreement, revealing the ability of the HarmoniX AFM tests to correctly characterize samples with complex morphologies such as injection molded objects.

3.4. Analysis of Elastic Modulus Distributions. The elastic modulus distributions contain much more data that can be used to completely characterize the sample structure and can be analyzed to discriminate between mechanically "hard" and "soft" areas. In Figure 6, an example of recorded elastic modulus distribution and cumulative curve is shown. The measuring points with an elastic modulus lower than the threshold value $\mathrm{Ms}(\mathrm{Ms}=1.1 \mathrm{GPa})$ have been defined as the "soft" contribution to the elastic modulus. Accordingly, the measuring points with an elastic modulus higher than the threshold value $\mathrm{Mh}(\mathrm{Mh}=2.1 \mathrm{GPa})$ have been defined as the "hard" contribution to the elastic modulus.

The choice of the Ms and Mh threshold values is completely arbitrary and not directly related to the mechanical properties of amorphous or crystalline phases. For each of the previous samples (reported in Figure 5), the three relative areas of the histogram identified by the selected threshold values (Ms and Mh) are reported in Figure 7.

The distribution of the soft and hard contributions is completely different in the three areas of the sample. Both the hard and the soft contributions are present in the spherulitic layer, whereas the intermediated moduli contribution covers more than $80 \%$ of the area. The soft contribution tends to disappear in the transition and in the shear layers, whereas the hard contribution increases. In particular, in the shear layer, the amount of hard contribution is the highest one.

As mentioned above, the threshold values are not related to the amount of amorphous and crystalline phases or to their mechanical properties. Nevertheless, the spherulitic core shows the highest amount of soft contribution, higher

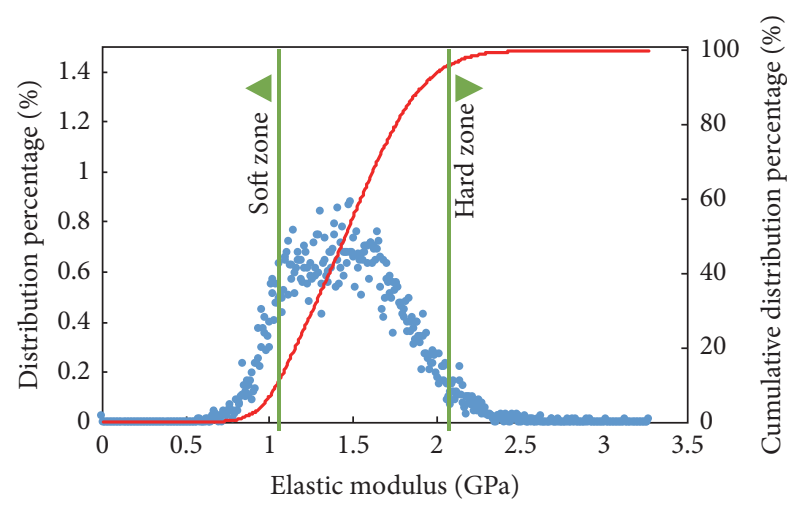

FIGURE 6: Example of analysis of the soft and hard zones in elastic modulus distribution for a position of the sample. Ms is the limit for the soft zone; $\mathrm{Mh}$ is the limit for the hard zone.

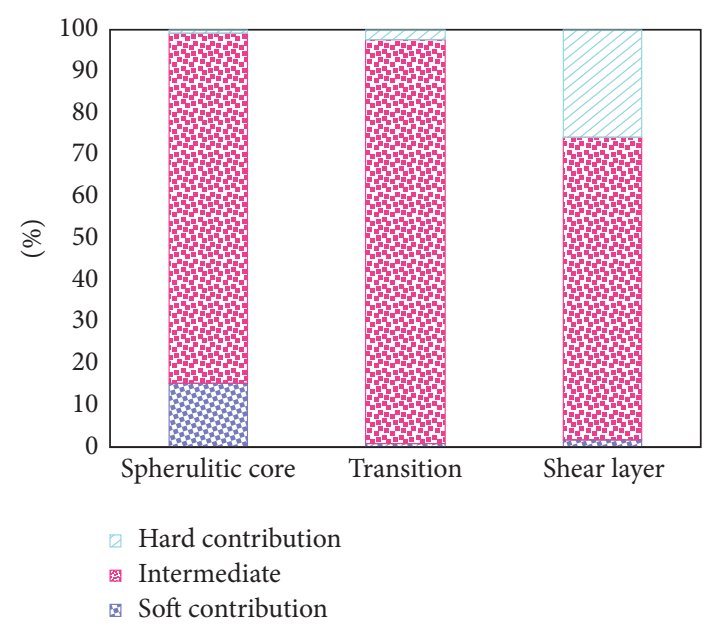

FIGURE 7: Relative distribution of the soft $(\mathrm{Ms}=1.1 \mathrm{GPa})$ and of the hard $(\mathrm{Mh}=2.1 \mathrm{GPa})$ regions present in the sample analyzed in Figure 5 .

also with respect to the transitions area where the adhesion force, which is related to the content of soft phase, is the highest one. This finding suggests that the soft contribution is due not only to the amount of the softer phases (i.e., amorphous and $\beta$-phase) but also to the level of molecular orientation.

\section{Conclusions}

HarmoniX AFM technique is found to be an important tool for measuring the nanomechanical characteristics of samples with complex morphology. It allows obtaining simultaneously maps of both elastic modulus and topography over the investigated area. Thus, the developed morphology can be correlated with the mechanical properties of the analyzed sample.

In this work, it has been demonstrated that HarmoniX AFM can also give accurate and reliable results on injectionmolded samples. In fact, the comparison between the elastic moduli measured by HarmoniX AFM with those obtained 
by indentation tests confirms the accuracy of the AFM based technique. However, to obtain reliable results in terms of elastic modulus, it is necessary to prepare the sample properly. For instance, the semicrystalline molded samples after the cutting procedures have to be chemically etched for an adequate time. Only in this way is it possible to obtain representative mechanical characteristics with narrow and bell shaped distributions.

A correct choice of the resolutions during HarmoniX acquisitions is also important to obtain correct elastic modulus measurements. The measurements are always accurate, reliable, and almost independent of the size of the investigated area if the selected size is large enough to include a significant number of structures (i.e., fibrils or spherulites). This means, especially for nonhomogeneous and anisotropic samples, that multiple tests must be preventively carried out in order to find an acceptable compromise between accuracy of the results and dimension of the area investigated.

Statistical analysis of the elastic modulus maps allows correlating the sample morphology with the relative content of soft and hard mechanical zones. Molded samples show the coexistence of high oriented shear layers with isotropic spherulitic zones. These shear layers, which show higher elastic modulus values, are characterized by a higher contribution of hard zones. On the opposite, the spherulitic core is characterized by significant content of soft zones.

All the experimental observations mentioned in this work suggest that the elastic modulus values depend not only on the crystalline degree but also on the orientation and molecular organization.

HarmoniX AFM could be certainly applied to smaller molecular structures, up to the nanometric dimensions of the lamellae. It ensures an accurate correlation between the molecular organization and the mechanical properties.

\section{Conflicts of Interest}

The authors declare that they have no conflicts of interest.

\section{Acknowledgments}

The authors would like to thank Mr. Fabio Docimo and Mr. Mario De Angioletti (IPCB-CNR) for their invaluable technical support.

\section{References}

[1] T. T. Ngo, J. G. Kohl, T. Paradise, A. Khalily, and D. L. Simonson, "Improving mechanical properties of thermoset biocomposites by fiber coating or organic oil addition," International Journal of Polymer Science, vol. 2015, Article ID 840823, 7 pages, 2015.

[2] Z. El-Qoubaa and R. Othman, "Tensile behavior of polyetheretherketone over a wide range of strain rates," International Journal of Polymer Science, vol. 2015, Article ID 275937, 9 pages, 2015.

[3] A. Flores, F. Ania, and F. J. Baltá-Calleja, "From the glassy state to ordered polymer structures: a microhardness study," Polymer, vol. 50, no. 3, pp. 729-746, 2009.
[4] G. Hochstetter, A. Jimenez, and J. L. Loubet, "Strain-rate effects on hardness of glassy polymers in the nanoscale range. Comparison between quasi-static and continuous stiffness measurements," Journal of Macromolecular Science B, vol. 38, no. 5-6, pp. 681-692, 1999.

[5] J. Giró-Paloma, J. J. Roa, A. M. Díez-Pascual et al., "Depthsensing indentation applied to polymers: a comparison between standard methods of analysis in relation to the nature of the materials," European Polymer Journal, vol. 49, no. 12, pp. 40474053, 2013.

[6] G. M. Pharr, W. C. Oliver, and F. R. Brotzen, "On the generality of the relationship among contact stiffness, contact area, and elastic modulus during indentation," Journal of Materials Research, vol. 7, no. 3, pp. 613-617, 1992.

[7] W. C. Oliver and G. M. Pharr, "Measurement of hardness and elastic modulus by instrumented indentation: advances in understanding and refinements to methodology," Journal of Materials Research, vol. 19, no. 1, pp. 3-20, 2004.

[8] B. Keerthika, Y. P. Cao, and D. Raabe, "Mechanical characterization of viscoelastic-plastic soft matter using spherical indentation," Computers, Materials and Continua, vol. 10, no. 3, pp. 243-258, 2009.

[9] R. Lesan-Khosh, R. Bagheri, and S. Asgari, "Nanoindentation of isotactic polypropylene: correlations between hardness, yield stress, and modulus on the local and global scales," Journal of Applied Polymer Science, vol. 121, no. 2, pp. 930-938, 2011.

[10] T. Jin, X. Niu, G. Xiao et al., "Effects of experimental variables on PMMA nano-indentation measurements," Polymer Testing, vol. 41, pp. 1-6, 2015.

[11] R. F. Gibson, "A review of recent research on nanoindentation of polymer composites and their constituents," Composites Science and Technology, vol. 105, pp. 51-65, 2014.

[12] L. Guadagno, C. Naddeo, V. Vittoria et al., "Cure behavior and physical properties of epoxy resin-filled with multiwalled Carbon nanotubes," Journal of Nanoscience and Nanotechnology, vol. 10, no. 4, pp. 2686-2693, 2010.

[13] A. M. Díez-Pascual, M. A. Gómez-Fatou, F. Ania, and A. Flores, "Nanoindentation in polymer nanocomposites," Progress in Materials Science, vol. 67, pp. 1-94, 2015.

[14] L. Shen, I. Y. Phang, T. Liu, and K. Zeng, "Nanoindentation and morphological studies on nylon 66/organoclay nanocomposites. II. Effect of strain rate," Polymer, vol. 45, no. 24, pp. 82218229, 2004

[15] T. Liu, I. Y. Phang, L. Shen, S. Y. Chow, and W.-D. Zhang, "Morphology and mechanical properties of multiwalled carbon nanotubes reinforced nylon-6 composites," Macromolecules, vol. 37, no. 19, pp. 7214-7222, 2004.

[16] F. Chavarria and D. R. Paul, "Morphology and properties of thermoplastic polyurethane nanocomposites: effect of organoclay structure," Polymer, vol. 47, no. 22, pp. 7760-7773, 2006.

[17] H. Lu, G. Huang, B. Wang, A. Mamedov, and S. Gupta, "Characterization of the linear viscoelastic behavior of singlewall carbon nanotube/polyelectrolyte multilayer nanocomposite film using nanoindentation," Thin Solid Films, vol. 500, no. 1-2, pp. 197-202, 2006.

[18] S. A. Shahdad, J. F. McCabe, and R. W. Wassell, "Developments in denture teeth to prevent softening by food solvents," Journal of Materials Science: Materials in Medicine, vol. 18, no. 8, pp. 1599-1603, 2007.

[19] T. Uchiyama, M. Suyama, M. M. Alam et al., "Layer structure formation in oriented poly(ethylene terephthalate) relating to 
micromechanical properties," Polymer, vol. 48, no. 2, pp. 542555, 2007.

[20] E. Wornyo, K. Gall, F. Yang, and W. King, "Nanoindentation of shape memory polymer networks," Polymer, vol. 48, no. 11, pp. 3213-3225, 2007.

[21] F. J. Baltá-Calleja, M. E. Cagiao, R. Adhikari, and G. H. Michler, "Relating microhardness to morphology in styrene/butadiene block copolymer/polystyrene blends," Polymer, vol. 45, no. 1, pp. 247-254, 2004.

[22] A. Flores, V. B. F. Mathot, G. H. Michler, R. Adhikari, and F. J. Baltá Calleja, "Novel aspects of microindentation hardness in very low crystallinity ethylene-1-octene copolymers: a model for deformation," Polymer, vol. 47, no. 15, pp. 5602-5609, 2006.

[23] A. Flores, D. Pietkiewicz, N. Stribeck, Z. Roslaniec, and F. J. Baltá Calleja, "Structural features of random polyester-amide copolymers as revealed by X-ray scattering and microindentation hardness," Macromolecules, vol. 34, no. 23, pp. 8094-8100, 2001.

[24] G. Venugopal, J. C. Veetil, N. Raghavan, V. Singh, A. Kumar, and A. Mukkannan, "Nano-dynamic mechanical and thermal responses of single-walled carbon nanotubes reinforced polymer nanocomposite thinfilms," Journal of Alloys and Compounds, vol. 688, pp. 454-459, 2016.

[25] F. Ania, G. Broza, M. F. Mina, K. Schulte, Z. Roslaniec, and F. J. Baltá-Calleja, "Micromechanical properties of poly(butylene terephthalate) nanocomposites with single- And multi-walled carbon nanotubes," Composite Interfaces, vol. 13, no. 1, pp. 3345, 2006.

[26] H. A. Shirazi, S. Mirmohammadi, M. Shaali, A. Asnafi, and M. R. Ayatollahi, "A constitutive material model for a commercial PMMA bone cement using a combination of nano-indentation test and finite element analysis," Polymer Testing, vol. 59, pp. 328-335, 2017.

[27] I. M. Orench, F. Ania, E. Baer, A. Hiltner, T. Bernal, and F. J. B. Calleja, "Basic aspects of microindentation in multilayered poly(ethylene terephthalate)/polycarbonate films," Philosophical Magazine, vol. 84, no. 18, pp. 1841-1852, 2004.

[28] S. Liparoti, A. Sorrentino, V. Speranza, and G. Titomanlio, "Multiscale mechanical characterization of iPP injection molded samples," European Polymer Journal, vol. 90, pp. 79-91, 2017.

[29] M. E. Dokukin and I. Sokolov, "Quantitative mapping of the elastic modulus of soft materials with HarmoniX and PeakForce QNM AFM modes," Langmuir, vol. 28, no. 46, pp. 16060-16071, 2012.

[30] A. Voss, R. W. Stark, and C. Dietz, "Surface versus volume properties on the nanoscale: elastomeric polypropylene," Macromolecules, vol. 47, no. 15, pp. 5236-5245, 2014.

[31] O. Sahin, S. Magonov, C. Su, C. F. Quate, and O. Solgaard, "An atomic force microscope tip designed to measure time-varying nanomechanical forces," Nature Nanotechnology, vol. 2, no. 8, pp. 507-514, 2007.

[32] C. J. Gòmez and R. Garcia, "Determination and simulation of nanoscale energy dissipation processes in amplitude modulation AFM," Ultramicroscopy, vol. 110, no. 6, pp. 626-633, 2010.

[33] B. V. Derjaguin, V. M. Muller, and Y. P. Toporov, "Effect of contact deformations on the adhesion of particles," Journal of Colloid And Interface Science, vol. 53, no. 2, pp. 314-326, 1975.

[34] M. Qu, F. Deng, S. M. Kalkhoran, A. Gouldstone, A. Robisson, and K. J. Van Vliet, "Nanoscale visualization and multiscale mechanical implications of bound rubber interphases in rubber-carbon black nanocomposites," Soft Matter, vol. 7, no. 3, pp. 1066-1077, 2011.

[35] P. Schön, K. Bagdi, K. Molnár, P. Markus, B. Pukánszky, and G. Julius Vancso, "Quantitative mapping of elastic moduli at the nanoscale in phase separated polyurethanes by AFM," European Polymer Journal, vol. 47, no. 4, pp. 692-698, 2011.

[36] G. Raj, C. Swalus, A. Guillet, M. Devillers, B. Nysten, and E. M. Gaigneaux, "Supramolecular organization in organic-inorganic heterogeneous hybrid catalysts formed from polyoxometalate and poly(ampholyte) polymer," Langmuir, vol. 29, no. 13, pp. 4388-4395, 2013.

[37] S. Liparoti, A. Sorrentino, and G. Titomanlio, "Fast cavity surface temperature evolution in injection molding: control of cooling stage and final morphology analysis," RSC Advances, vol. 6, pp. 99274-99281, 2016.

[38] S. Liparoti, A. Sorrentino, G. Guzman, M. Cakmak, and G. Titomanlio, "Fast mold surface temperature evolution: relevance of asymmetric surface heating for morphology of iPP molded samples," RSC Advances, vol. 5, no. 46, pp. 36434-36448, 2015.

[39] S. Liparoti, A. Sorrentino, G. Guzman, M. Cakmak, and G. Titomanlio, "Effect of fast mold surface temperature evolution on iPP part morphology gradients," in Proceedings of the 31st International Conference of the Polymer Processing Society (PPS '16), AIP Conference Proceeding, p. 170001, 2016.

[40] S. Liparoti, V. Speranza, R. Pantani, and G. Titomanlio, "Fast temperature evolution on the mold surface: analysis and simulation," AIP Conference Proceedings, Article ID 020014, 2016.

[41] S. Liparoti, G. Titomanlio, and A. Sorrentino, "Analysis of asymmetric morphology evolutions in iPP molded samples induced by uneven temperature field," AIChE Journal, vol. 62, no. 8, pp. 2699-2712, 2016.

[42] S. Liparoti, T. M. Hunag, A. Sorrentino, G. Titomanlio, and M. Cakmak, "Rapid control of mold temperature during injection molding process," in Proceedings of the 30th International Conference of Polymer Processing Society, AIP Conference Proceeding, Cleveland, Ohio, USA, 2014.

[43] V. Volpe and R. Pantani, "Foam injection molding of poly(lactic) acid: effect of back pressure on morphology and mechanical properties," Journal of Applied Polymer Science, vol. 132, p. 42612, 2015.

[44] V. Volpe and R. Pantani, "Effect of processing condition on properties of polylactic acid parts obtained by foam injection molding," Journal of Cellular Plastics, pp. 1-12, 2016.

[45] R. Pantani, F. De Santis, V. Speranza, and G. Titomanlio, "Modeling morphology evolution during injection molding of thermoplastic polymers," in Proceedings of the PPS-30: The 30th International Conference of the Polymer Processing Society (AIP '15), vol. 1664, Cleveland, Ohio, USA, 2015.

[46] R. Pantani, I. Coccorullo, V. Volpe, and G. Titomanlio, "Shearinduced nucleation and growth in isotactic polypropylene," Macromolecules, vol. 43, no. 21, pp. 9030-9038, 2010.

[47] R. Pantani, V. Speranza, and G. Titomanlio, "Simultaneous morphological and rheological measurements on polypropylene: effect of crystallinity on viscoelastic parameters," Journal of Rheology, vol. 59, no. 2, pp. 377-390, 2015.

[48] R. Pantani, I. Coccorullo, V. Speranza, and G. Titomanlio, "Modeling of morphology evolution in the injection molding process of thermoplastic polymers," Progress in Polymer Science, vol. 30, no. 12, pp. 1185-1222, 2005.

[49] R. Pantani, V. Speranza, and G. Titomanlio, "Evolution of iPP relaxation spectrum during crystallization," Macromolecular Theory and Simulations, vol. 23, no. 4, pp. 300-306, 2014. 
[50] A. Sorrentino and R. Pantani, "Determination of the effect of pressure on viscosity of an isotactic polypropylene," Polymer Bulletin, vol. 70, no. 7, pp. 2005-2014, 2013.

[51] R. Pantani, V. Speranza, I. Coccorullo, and G. Titomanlio, "Morphology of injection moulded iPP samples," Macromolecular Symposia, vol. 185, pp. 309-326, 2002.

[52] F. De Santis, R. Pantani, V. Speranza, and G. Titomanlio, "Analysis of shrinkage development of a semicrystalline polymer during injection molding," Industrial and Engineering Chemistry Research, vol. 49, no. 5, pp. 2469-2476, 2010.

[53] H. M. White and D. C. Bassett, "On row structures, secondary nucleation and continuity in $\alpha$-polypropylene," Polymer, vol. 39, no. 14, pp. 3211-3219, 1998.

[54] H. Gojzewski, B. Imre, C. Check, R. Chartoff, and J. Vancso, "Mechanical mapping and morphology across the length scales unveil structure-property relationships in polycaprolactone based polyurethanes," Journal of Polymer Science, Part B: Polymer Physics, vol. 54, pp. 2298-2310, 2016.

[55] C. Dietz, M. Zerson, C. Riesch et al., "Nanotomography with enhanced resolution using bimodal atomic force microscopy," Applied Physics Letters, vol. 92, no. 14, Article ID 143107, 2008.

[56] R. Pantani, A. Sorrentino, V. Speranza, and G. Titomanlio, "Molecular orientation in injection molding: experiments and analysis," Rheologica Acta, vol. 43, no. 2, pp. 109-118, 2004.

[57] R. Pantani, V. Speranza, and G. Titomanlio, "Relevance of crystallisation kinetics in the simulation of the injection molding process," International Polymer Processing, vol. 16, no. 1, pp. 61$71,2001$.

[58] R. F. Landel and L. E. Nielsen, Mechanical Properties of Polymers and Composites, CRC Press, 1993.

[59] S. Liparoti, A. Sorrentino, and G. Titomanlio, "Rapid control of mold temperature during injection molding process: effect of packing pressure," in Polymer Processing with Resulting Morphology and Properties: Feet in the Present and Eyes in the Future: Proceedings of the GT70 International Conference-Salerno (Italy), 2015, AIP Conference Proceedings, p. 20052, 2015.

[60] F. De Santis and R. Pantani, "Development of a rapid surface temperature variation system and application to microinjection molding," Journal of Materials Processing Technology, vol. 237, pp. 1-11, 2016.

[61] M. R. Kamal, D. M. Kalyon, and J. M. Dealy, "An integrated experimental study of the injection molding behavior of some polyethylene resins," Polymer Engineering \& Science, vol. 20, no. 17, pp. 1117-1125, 1980.

[62] F. De Santis, R. Pantani, and G. Titomanlio, "Effect of shear flow on spherulitic growth and nucleation rates of polypropylene," Polymer, vol. 90, pp. 102-110, 2016.

[63] T. Labour, G. Vigier, R. Séguéla, C. Gauthier, G. Orange, and Y. Bomal, "Influence of the $\beta$-crystalline phase on the mechanical properties of unfilled and calcium carbonate-filled polypropylene: ductile cracking and impact behavior," Journal of Polymer Science, Part B: Polymer Physics, vol. 40, no. 1, pp. 31-42, 2002.

[64] G. Kalay and M. J. Bevis, "Processing and physical property relationships in injection-molded isotactic polypropylene. 2. Morphology and crystallinity," Journal of Polymer Science, Part B: Polymer Physics, vol. 35, no. 2, pp. 265-291, 1997. 

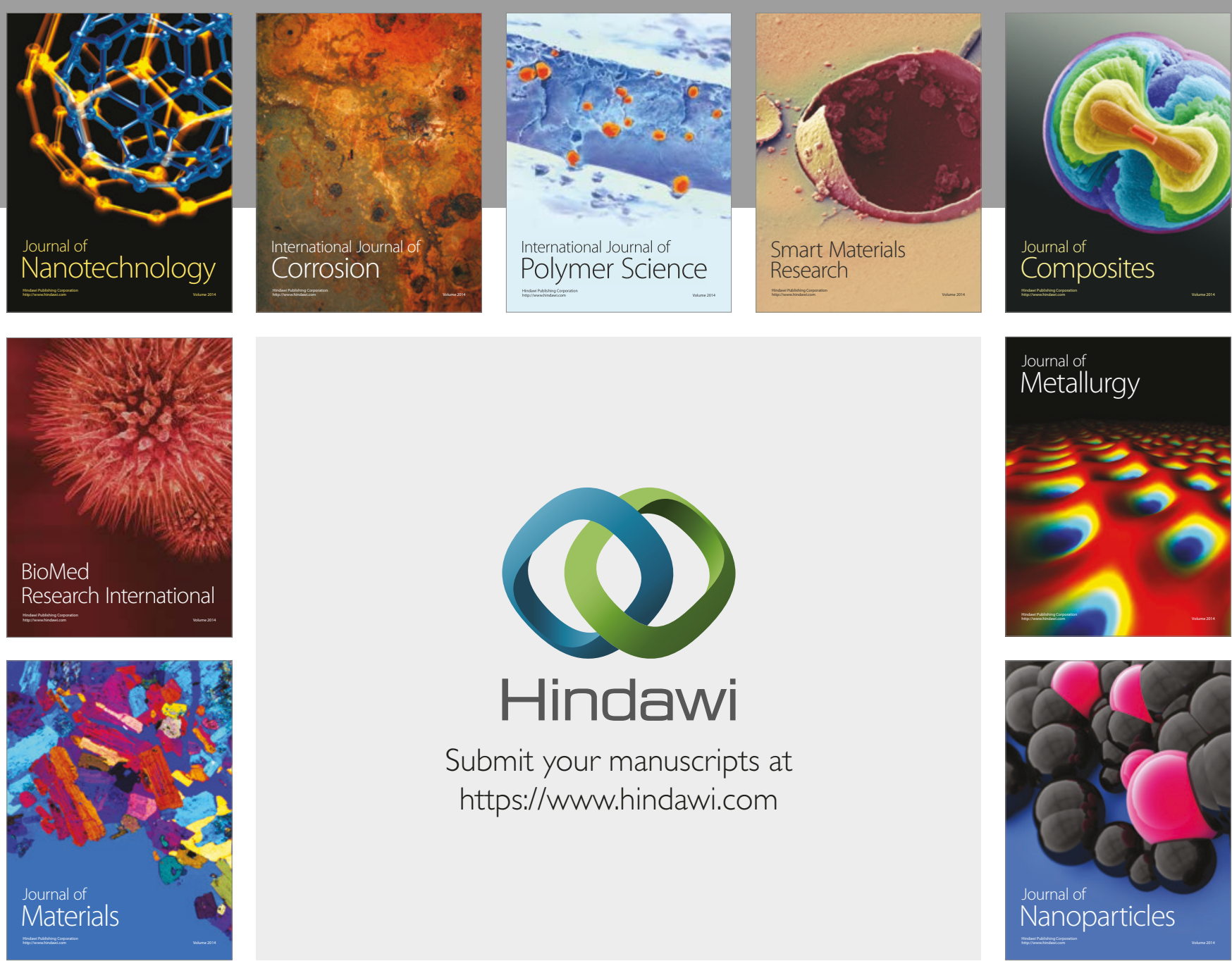

\section{Hindawi}

Submit your manuscripts at

https://www.hindawi.com
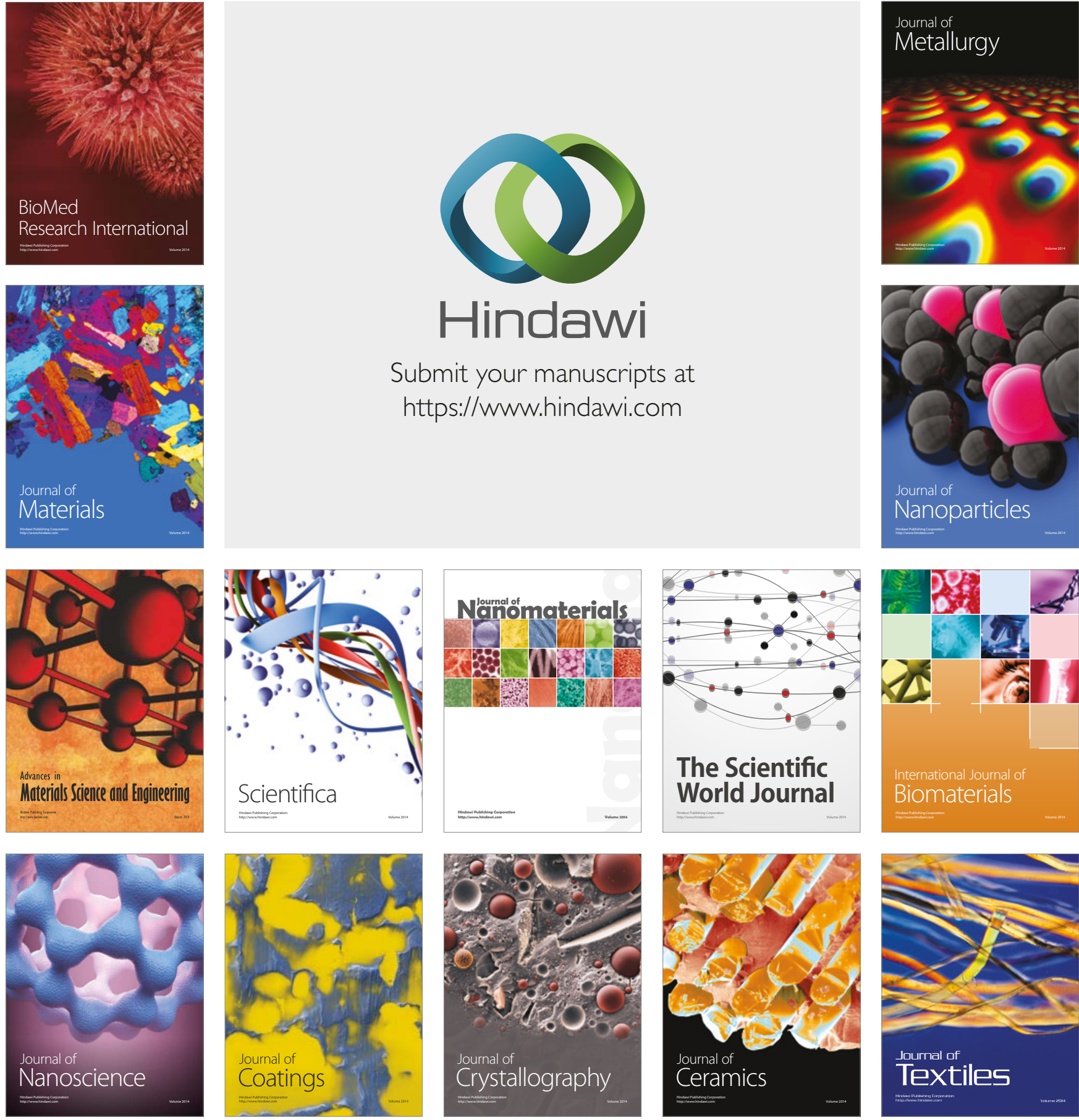

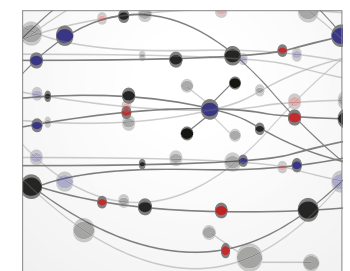

The Scientific World Journal
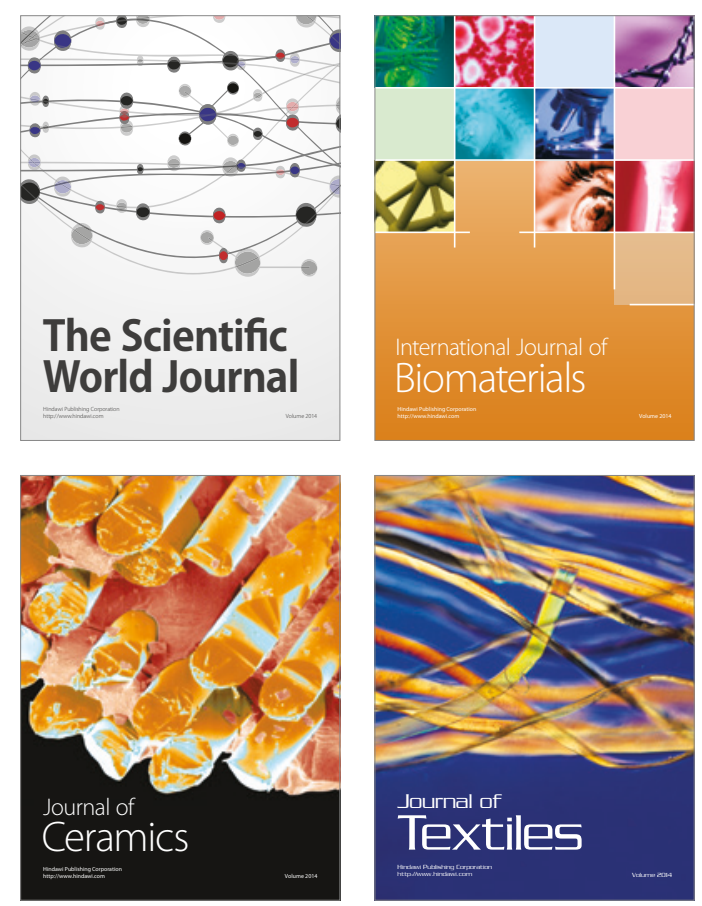